\title{
Study of Process Affected by Electrolyte Concentration through Microarc Oxidation on the TC4 Alloy Surface
}

\author{
Fengbiao Wang*, Yongqing Wang, Bo Hou, Jiakun Wu, Yapeng Li \\ School of Mechanical Engineering, Dalian University of Technology, Dalian, China \\ Email: "wfb00@163.com
}

Received 3 January 2015; accepted 19 January 2015; published 23 January 2015

Copyright (C) 2015 by authors and OALib.

This work is licensed under the Creative Commons Attribution International License (CC BY). http://creativecommons.org/licenses/by/4.0/

(c) (i) Open Access

\section{Abstract}

This paper aims to achieve the prepared functional coatings containing a specific ratio of calcium and phosphorus, and guide the rational allocation of chemical reagents. On the medicinal titanium alloy surface the calcium biocoating and phosphorus biocoating were fabricated by micro arc oxidation (MAO) process. The coating morphology and elemental composition were observed by scanning electron microscopy (SEM) and energy dispersive spectrometer (EDS). Wear resistant test on the coating surface was executed. The effect regulars of different concentrations and different molar ratio of electrolyte on the calcium and phosphorus content of medical TC4 alloy coating on micro arc oxidation system were researched, and the effects of electrolyte concentration on the molar ratio of calcium and phosphorus in the coating were also studied. The experimental results show that, with the increase of the electrolyte concentration, calcium content and phosphorus content in the coating are all decreased. But the ratio of calcium and phosphorus in the coating is increased, and the concentration of $\mathrm{Ca} / \mathrm{P}$ molar ratio is higher, while calcium content and phosphorus content in coating are all lower. Wear resistant test shows that proper electrolyte concentration is helpful to improve the surface properties of coating. So if it wants to prepare one certain $\mathrm{Ca} / \mathrm{P}$ molar ratio biocoating, the ratio can determine the different electrolyte concentrations of $\mathrm{Ca} / \mathrm{P}$ molar ratio, and at last determine roughly the ratio of the compound reagent.

\section{Keywords}

Calcium and Phosphorus Ratio, Micro-Arc Oxidation, Electrolyte Concentration, Wear Resistant

Subject Areas: Biological Materials, Composite Material, Material Experiment

\footnotetext{
${ }^{*}$ Corresponding author.
}

How to cite this paper: Wang, F.B., Wang, Y.Q., Hou, B., Wu, J.K. and Li, Y.P. (2015) Study of Process Affected by Electrolyte Concentration through Microarc Oxidation on the TC4 Alloy Surface. Open Access Library Journal, 2: e1199. 


\section{Introduction}

As a kind of typical biological activity, material calcium phosphate ceramic has the similar chemical composition and structure with the hard tissue of human body, and is the main inorganic component of human bone and teeth. When implanted in the human body, the kind of material can not only lead to bone-formation, but also form synostosis with new bone. With the muscle, ligament or subcutaneous tissue cultivation calcium phosphate ceramic can closely integrate with the organization, at the same time it is no inflammation or irritation reaction [1]-[4]. Therefore, calcium phosphate ceramic material is often used for artificial bone, artificial joint, artificial tooth and bone filling materials, and it is also used in clinical. Surface modification of biological coating on Titanium alloy is included in electroplating, spraying film and high temperature synthesis, but different level of the film and substrate adhesion is poor shortcoming. So the stripping phenomenon is inevitable after implanted, which leads to implant failure or a shorter implant life.

MAO is an economic, efficient and environmentally friendly technology for surface treatment on lightweight metals (aluminum, magnesium, zirconium, titanium, etc.) or metal alloys [5]-[8]. Many properties of MAO coating including bonding strength with the substrate, thickness of film, micro hardness, anti-wear and corrosion resistance are all relatively excellent [9]-[12]. But the coating outside in general is a loose layer, while the internal one is a dense layer. Usually related to dense layer, the loose layer is thick and loose organization, and mainly consists of anatase phase with relatively low hardness for the Ti alloy MAO coating [13]-[16].

But in the micro arc oxidation process for preparing biocoating of on titanium alloy surface, the composition of formed coating is greatly affected by the electrolyte concentration, while the electrolyte concentration is mainly decided by the content of calcium and phosphorus in chemical reagent solution. When the electrolyte concentration wants to obtain one coating with a certain calcium/phosphorus ratio relationship, the chemical reagent allocation becomes the key factor restricting the success of the experiment. So, we must research the relationship of concentration of solution and coating component of calcium and phosphorus.

\section{Experimental Details}

\subsection{Experimental Material}

Experiment treated substrate material is TC4 titanium alloy (mass fraction of elements, such as Table 1).

TC4 alloy plates were used as specimens whose measurement is $80 \mathrm{~mm} \times 40 \mathrm{~mm} \times 3.5 \mathrm{~mm}$. The plates were ground with 350,700 and $1000^{\#}$ abrasive papers, flushed with acetone and distilled water for $20 \mathrm{~min}$, and dried at $40^{\circ} \mathrm{C}$.

\subsection{Prepared Electrolyte}

Prepared electrolyte is as shown in Table 2. The concentration of $10 \%$ ammonia water was used to regulated $\mathrm{pH}$ $=11-12$.

\subsection{Micro Arc Oxidation Equipment and Electrical Parameters}

The $20 \mathrm{KW}$ DC/AC micro arc oxidation device of the laboratory developed was used to treat the specimens, the equipment is composed of pulse power supply, electrolytic tank, mixing system and cooling system. The positive pole of the power supply was connected with the specimen clamped by special and as anode, then stainless steel was as cathode electrolytic tank.

The applied voltages (effective values of voltage) of $510 \mathrm{~V}$ were used to prepare MAO coatings. The power waveform, frequency and duty cycle were unipolar pulse, $500 \mathrm{~Hz}$ and $20 \%$, respectively; it was one specimen for one prepared solution, and the number was NO. 1 - NO. 12.

\subsection{Analysis Equipment}

JEOL-JSM-5900LV scanning electron microscope (SEM) was used to observe coating morphology and structure. The electronic energy spectrum analyzer (EDS) was used to analyse the $\mathrm{Ca}$ and $\mathrm{P}$ element content in the coating; The universal meter was used to measure the electrolyte voltage; The friction tests of the film were carried out by friction wear testing machine with the type of MMW-1; JA type Tailong electronic balance was used to weigh wear, and its accuracy is $0.001 \mathrm{~g}$. 
Table 1. TC4 composition [wt $\%$ ].

\begin{tabular}{cccccc}
\hline $\mathrm{Al}$ & $\mathrm{V}$ & $\mathrm{O}$ & $\mathrm{Fe}$ & others & Ti \\
$5.5-6.75$ & $3.5-4.5$ & $0.2-0.3$ & $\leq 0.5$ & $<0.3$ & allowance \\
\hline
\end{tabular}

Table 2. Prepared electrolyte.

\begin{tabular}{cccccc}
\hline Serial number & $\begin{array}{c}\left(\mathrm{CH}_{3} \mathrm{COO}\right)_{2} \mathrm{Ca} \\
(\mathrm{mol} / \mathrm{L})\end{array}$ & $\begin{array}{c}\mathrm{NH}_{4} \mathrm{H}_{2} \mathrm{PO}_{4} \\
(\mathrm{~mol} / \mathrm{L})\end{array}$ & $\begin{array}{c}\mathrm{NaH}_{2} \mathrm{PO}_{4} \\
(\mathrm{~mol} / \mathrm{L})\end{array}$ & $\begin{array}{c}\mathrm{EDTA}-2 \mathrm{Na} \\
(\mathrm{mol} / \mathrm{L})\end{array}$ & Mole ratio of $\mathrm{Ca}$ and $\mathrm{P}$ \\
\hline 1 & 0.024 & 0.012 & 0.008 & 0.005 & 1.2 \\
2 & 0.024 & 0.009 & 0.006 & 0.006 & 1.6 \\
3 & 0.024 & 0.007 & 0.005 & 0.007 & 2.0 \\
4 & 0.048 & 0.024 & 0.016 & 0.01 & 1.2 \\
5 & 0.048 & 0.018 & 0.012 & 0.012 & 2.0 \\
6 & 0.048 & 0.014 & 0.01 & 0.014 & 1.2 \\
7 & 0.072 & 0.036 & 0.024 & 0.015 & 1.6 \\
8 & 0.072 & 0.027 & 0.018 & 0.018 & 2.0 \\
10 & 0.072 & 0.021 & 0.015 & 0.021 & 1.2 \\
11 & 0.096 & 0.048 & 0.032 & 0.02 & 1.6 \\
\hline
\end{tabular}

\section{Result and Discussion}

\subsection{Effect of Solution Concentration on Biocoating Morphology}

In the electrolyte molar ratio of $\mathrm{Ca}$ and $\mathrm{P}$ as to 1.6 , surface and section morphology of micro arc oxidation coatings prepared with different concentration are shown in Figure 1 and Figure 2. The figure shows the coating surface pore is become larger with electrolyte concentration increased, and coating is become coarse, as well as dense layer thickness increased.

\subsection{Effect of Solution Concentration on Biocoating Composition}

Micro arc oxidation test solution is mainly composed of $\mathrm{Na}^{+}, \mathrm{Ca}^{2+}, \mathrm{OH}^{-}, \mathrm{H}_{2} \mathrm{PO}_{4}^{-}, \mathrm{NH}_{4}^{+}, \mathrm{CH}_{3} \mathrm{COO}^{-}$, $\mathrm{Ca}\left(\mathrm{H}_{2} \mathrm{PO}_{4}\right)_{2}, \mathrm{Ca}(\mathrm{OH})_{2}$, and $\mathrm{Ca}_{3}\left(\mathrm{PO}_{4}\right)_{2}$ particles. The $\mathrm{Ca}(\mathrm{OH})_{2}$ and $\mathrm{Ca}_{3}\left(\mathrm{PO}_{4}\right)_{2}$ is insoluble in water, but the colloidal particles with negative charge can be formed with negatively in water, in addition calcium and phosphorus element can exist by $\mathrm{Ca}^{2+}$ and $\mathrm{PO}_{4}^{3-}$ formation in electrolyte.

Figure 3(a) and Figure 3(b) respectively show the changes of calcium and phosphorus content of biocoating with different electrolyte concentration. In Figure 3 it is can be seen with the same electrolyte concentration, if solution molar ratio of $\mathrm{Ca} / \mathrm{P}$ in electrolyte is lower, on the contrary, it is higher for the calcium and phosphorus content in the coating. But for the electrolyte of molar ratio of $\mathrm{Ca} / \mathrm{P}$ determined, with the concentration improvement of $\left(\mathrm{CH}_{3} \mathrm{COO}\right)_{2} \mathrm{Ca}$ and $\mathrm{NH}_{4} \mathrm{H}_{2} \mathrm{PO}_{4}$, in biocoating the calcium and phosphorus content is not increased but decreased, as well as for the higher concentration concentration, in the coating the calcium content is decreased slowly, while the content of phosphorus in the whole concentration range is rapid decline, and the rate of decline is significantly greater than that of calcium, especially for the lower molar ratio $\mathrm{Ca} / \mathrm{P}$ in electrolyte.

The main reasons of these phenomena are as follows, with electrolyte solution concentration increased, more charged particles of calcium and phosphorus are produced, which is contribute to increase the conductive performance of the electrolyte, and the equivalent resistance of the electrolyte is decreases, who lead to the pressure drop reduced, as shown in Figure 4. When the electrolyte concentration is increased from $8 \mathrm{~g} / \mathrm{L}$ to $32 \mathrm{~g} / \mathrm{L}$, at the same time in the electrolyte the content of the colloidal particles of $\mathrm{Ca}(\mathrm{OH})_{2}$ and $\mathrm{Ca}_{3}\left(\mathrm{PO}_{4}\right)_{2}$ is improved, and these colloidal particles play an impedance function, which could make the electrolyte pressure improved. The solution, biocoating and titanium alloy substrate is roughly equivalent circuit of series state, so when in the micro arc oxidation stability stage, it will make the pressure drop in micro arc discharge channels decreased, who 


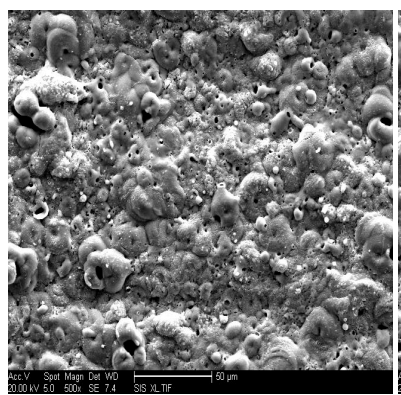

(a)

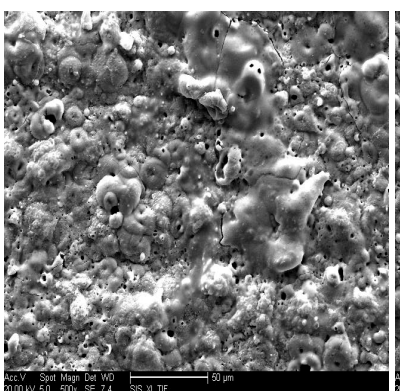

(b)

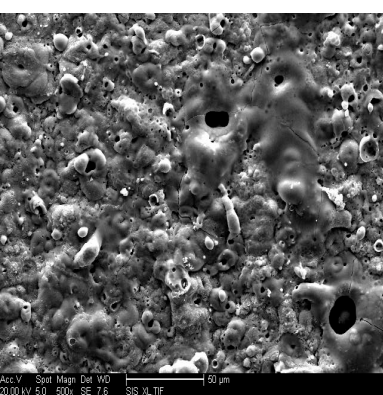

(c)

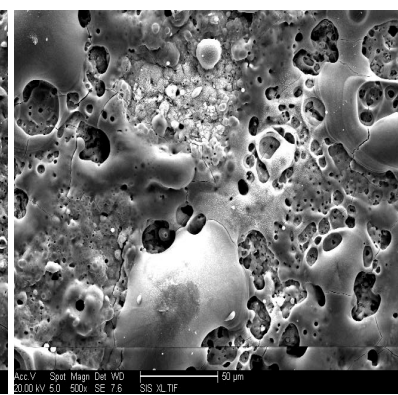

(d)

Figure 1. Surface morphology of biocoating of different electrolyte concentration: (a) $8 \mathrm{~g} / \mathrm{L}$; (b) $16 \mathrm{~g} / \mathrm{L}$; (c) $24 \mathrm{~g} / \mathrm{L}$; (d) $32 \mathrm{~g} / \mathrm{L}$.

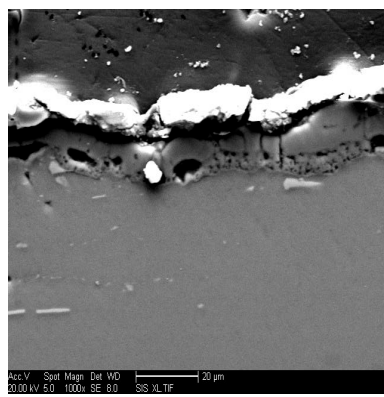

(a)

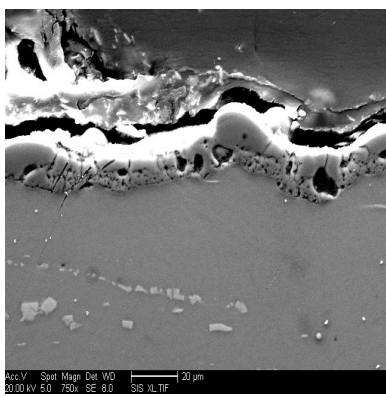

(b)

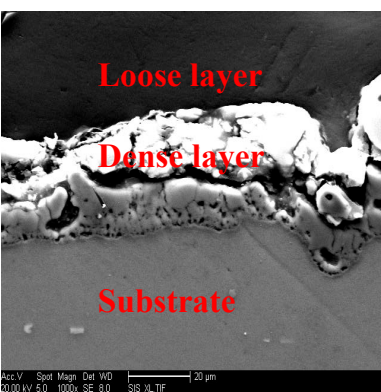

(c)

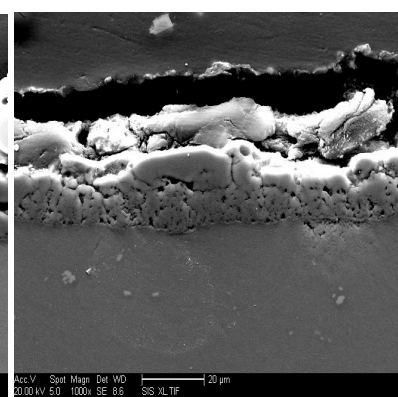

(d)

Figure 2. Section morphology of biocoating of different electrolyte concentration: (a) $8 \mathrm{~g} / \mathrm{L}$; (b) $16 \mathrm{~g} / \mathrm{L}$; (c) $24 \mathrm{~g} / \mathrm{L}$; (d) 32 g/L.

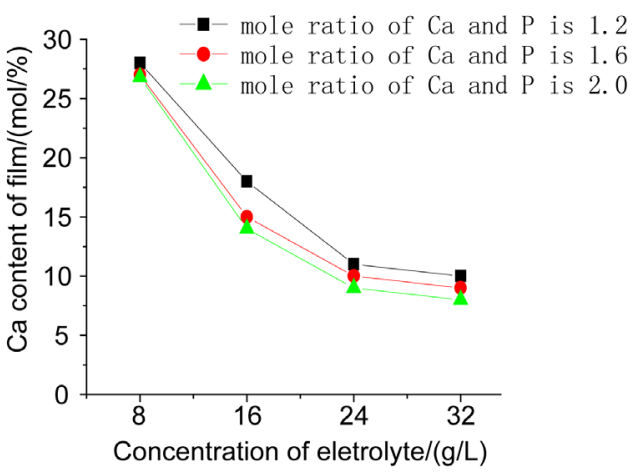

(a)

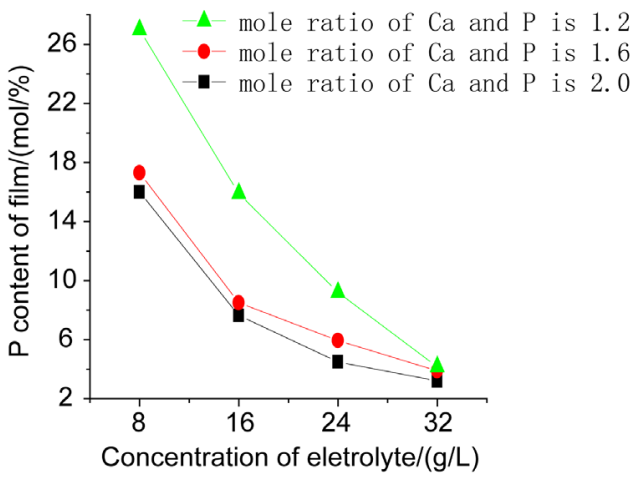

(b)

Figure 3. Effect of electrolyte concentration on biocoating: (a) Effect of Ca content; (b) Effect of P content.

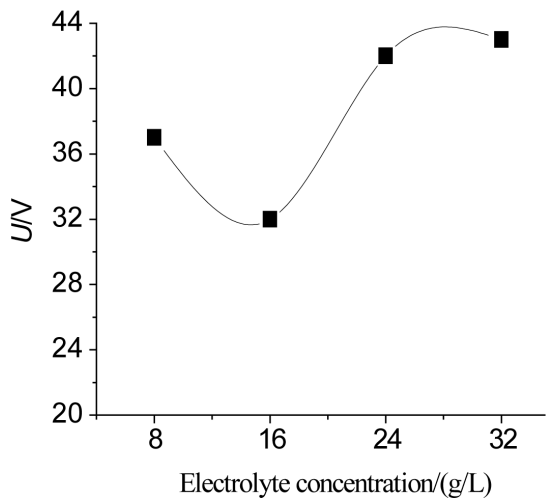

Figure 4. Effect of electrolyte concentration on voltage. 
directly affects the gas discharge breakdown state, and indirectly affects the calcium and phosphate ions number into the layer and combined to form calcium phosphate salt opportunity, which leads calcium and phosphorus content in the coating is decreased. But when the electrolyte concentration is increased to a certain extent, and colloidal particles concentration is close to saturation, the voltage drop of electrolyte is tend to the steady state, so the calcium and phosphorus content in the coating is changed slowly. Because the phosphorus than calcium ion is more difficult to get into discharge channel [12], at the same time with the same electrolyte concentration, Compared with the calcium ion concentration is increased, the phosphorus ion content is on the decline, so in the coating the phosphorus ion content is decreased significantly. So in the same concentration, in the electrolyte of lower $\mathrm{Ca} / \mathrm{P}$ molar ratio the higher phosphorus content should be guaranteed, which will ensure that there are more $\mathrm{P}$ ions to get into the discharge channel, and there is more calcium and phosphorus is contained in the coating.

It is also seen in Figure 3, with the increase of the electrolyte concentration, although calcium and phosphorus content is increased, it cannot guarantee that the calcium and phosphorus content in the coating is increased at the same time, on the contrary, it is decreased. So the configured electrolyte concentration is too should not be too large, and the same for molar ratio of $\mathrm{Ca} / \mathrm{P}$ in electrolyte. But because of the calcium in addition to is participated to be prepared the biocoating, also is fabricated other substances in electrolyte, so as to make the calcium content is relatively surplus in the electrolyte.

\subsection{Relationship of Ca/P Ratio in Coating and Electrolyte Concentration}

Although calcium and phosphorus compounds concentration is changed compared to the same ratio in electrolyte, in the biocoating calcium and phosphorus content change is not the same trend, which causes that although $\mathrm{Ca} / \mathrm{P}$ molar ratio is consistently kept, the mole ratio in the biological coating is in change. Following to electrolyte concentration of calcium and phosphorus compounds is increased, as well as the $\mathrm{Ca} / \mathrm{P}$ molar ratio in biological coating is the same trend, and in the electrolyte of $\mathrm{Ca} / \mathrm{P}$ molar ratio with bigger value it is more significant changes, as shown in Figure 5. In the electrolyte of $\mathrm{Ca} / \mathrm{P}$ molar ratio values with 1.2, 1.6 and 2, Ca/P molar ratio of hydroxyapatite (1.67) is as a sign of biocoating $\mathrm{Ca} / \mathrm{P}$ molar ratio, if wants to obtain the biological coating of ratio of 1.67, the MAO experiment concentration of the electrolyte are about $26.4,16.2$ and $14.5 \mathrm{~g} / \mathrm{L}$, respectively, as shown in Figure 5 with "*”" correspond to the abscissa values shown.

This conclusion can guide the configuration of electrolyte in the process of micro arc oxidation, and then determine reasonably proportioning of the calcium and phosphorus compound reagent.

\subsection{Effect of Solution Concentration on the Wear Resistance of Biocoating}

From the wear capacity in Figure 6 and wear time curve, it can be seen that for the electrolyte concentration of $16 \mathrm{~g} / \mathrm{L}$ and $24 \mathrm{~g} / \mathrm{L}$, the former wear capacity (in $30 \mathrm{~min}$ ) are also less than $8 \mathrm{~g} / \mathrm{L}$, but the concentration of electrolyte is $32 \mathrm{~g} / \mathrm{L}$, it is the larger amount of wear and tear at the same time. That is mainly due to the more thick

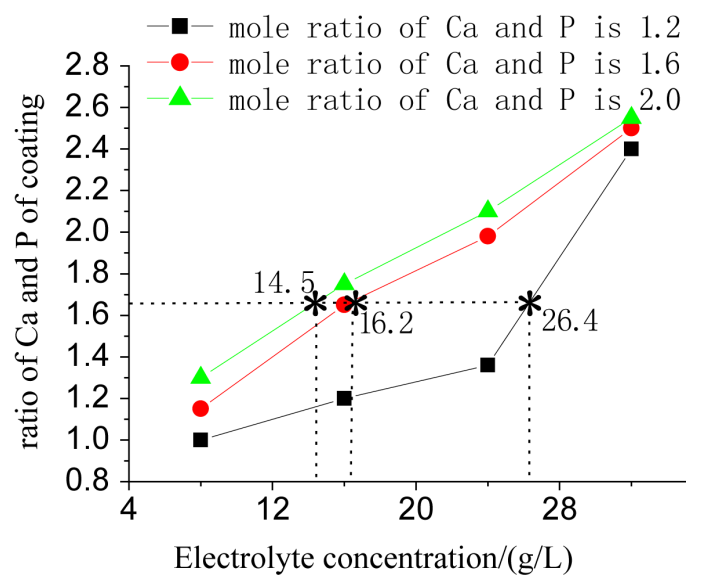

Figure 5. Relationship of $\mathrm{Ca}$ and $\mathrm{P}$ of biocoating and electrolyte concentration. 


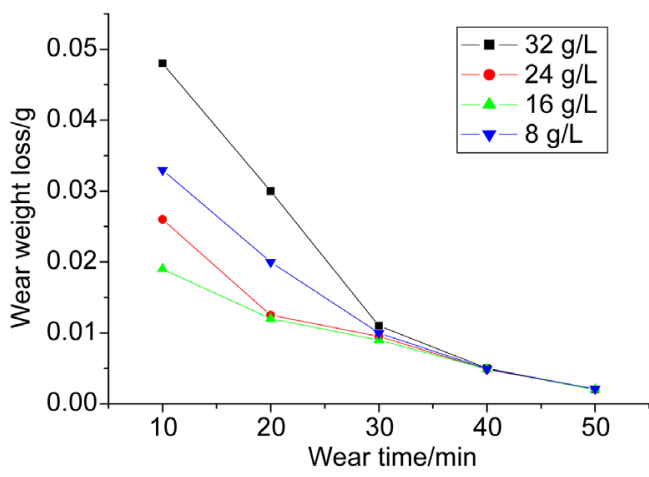

Figure 6. Relationship of wear time and wear weight loss of the MAO coatings at different electrolyte concentration of 1.6 mole ratio of $\mathrm{Ca}$ and $\mathrm{P}$.

loose layer of biocoating which is prepared in high electrolyte concentration condition, so the wear resistance is poor, and early wear mainly is occurred in the loose layer, ultimately, the wear capacity is larger. To the lower concentration electrolyte level $(8 \mathrm{~g} / \mathrm{L})$, because of the lower concentration the process of growth of the prepared coating is not sufficient, which does not meet the minimum requirements of micro arc oxidation process for electrolyte concentration. So it is not sufficient for micro arc oxidation discharge in the parts of micro area, and the plasma discharge fully is not unrealized, the prepared coating is mainly in the loose layer with relatively thicker, who affected the effective generation of dense layer, so the wear amount is large in the early stage. This shows that proper concentration is helpful to improve the surface properties of the biocoating, and the coating surface is smooth and dense, as shown in Figure 2. In the later period of wear because of contact of the friction pair and the dense layer (In the early of outer basic is nearly worn off), and because the biological membrane pores can store lubricating oil to improve the lubrication effect, and later the wear volume is gradually reduced and finally tends to zero.

\section{Conclusions}

1) The effect of calcium and phosphorus molar content in the biocoating with electrolyte concentration is studied. With the electrolyte concentration increased, the calcium content and phosphorus content in the coating are all decreased, while the change trend of the content of phosphorus is more obvious;

2) The effect of calcium and phosphorus molar ratio in the biocoating with electrolyte concentration is studied too. With electrolyte concentration increased, the molar ratio of calcium and phosphorus in the coating is increased at the same time;

3) The relationship of biological membrane calcium to phosphorus ratio and electrolyte concentration is researched. If we want to prepare a biocoating with one calcium phosphorus ratio, different electrolyte concentration of $\mathrm{Ca} / \mathrm{P}$ ratio can be confirmed by it, and reagent ratio of calcium and phosphorus compounds can be determined approximately;

4) The too high or too low electrolyte concentration will all affect wear resistance of the biocoating, but the suitable amount of electrolyte concentrations contributes to improvement of surface properties of the coating.

\section{References}

[1] Mcpherson, R., Gane, N. and Bastow, T. (1995) Structural Characterization of Plasma Sprayed Hydroxyapatite Coatings. Journal of Materials Science-Materials in Medicine, 6, 327-334. http://dx.doi.org/10.1007/BF00120300

[2] Qiao, J.Q. and Wang, F.B. (2012) Fracture Mechanics of Composite Ceramic Coating Prepared by Micro-Arc Oxidation on Biomedical Titanium Alloy. Plating and Finishing, 34, 18-23.

[3] Mendes, S.C., Reis, R.L., Bovell, Y.P., et al. (2001) Biocompatibility Testing of Novel Starch-Based Materials with Potential Application in Orthopaedic Surgery: A Preliminary Study. Biomaterials, 22, 2057-2064. http://dx.doi.org/10.1016/S0142-9612(00)00395-1

[4] Guan, Y.J., Xia, Y. and Li, G. (2008) Growth Mechanism and Corrosion Behavior of Ceramic Coatings on Aluminum Produced by Auto Control AC Pulse PEO. Surface and Coatings Technology, 202, 4602-4612. 
[5] Ishizawa, H. and Ogino, M. (1995) Formation and Characterization of Anodic Titanium Oxide Films Containing Ca and P. Journal of Biomedical Materials Research, 29, 65-72. http://dx.doi.org/10.1002/jbm.820290110

[6] Yerokhin, A.L., Nie, X., Leyland, A., Matthews, A. and Dowey, S.J. (1999) Plasma Electrolysis for Surface Engineering. Surface \& Coatings Technology, 122, 73-93. http://dx.doi.org/10.1016/S0257-8972(99)00441-7

[7] Sul, Y.T. (2003) The Significance of the Surface Properties of Oxidized Titanium to the Bone Response: Special Emphasis on Potential Biochemical Bonding of Oxidized Titanium Implant. Biomaterials, 24, 3893-3907. http://dx.doi.org/10.1016/S0142-9612(03)00261-8

[8] Harimkar Sandip, P. and Dahotre Narendra, B. (2008) Microindentation Fracture Behavior of Laser Surface Modified Alumina Ceramic. Scripta Materialia, 58, 545-553.

[9] Khorasanian, M., Dehghan, A., Shariat, M.H., et al. (2011) Microstructure and Wear Resistance of Oxide Coatings on Ti-6Al-4V Produced by Plasma Electrolytic Oxidation in an Inexpensive Electrolyte. Surface and Coatings Technology, 206, 1495-1502.

[10] Son, W.W., Zhu, X., Shin, H.I., Ong, J.L., et al. (2003) In Vivo Histological Response to Anodized and Anodized/ Hydrothermally Treated Titanium Implants. Journal of Biomedical Materials Research Part B: Applied Biomaterials, 66B, 520-525. http://dx.doi.org/10.1002/jbm.b.10042

[11] Li, L.H., Kong, Y.M., et al. (2004) Improved Biological Performance of Ti Implants Due to Surface Modification by Microarc oxidation. Biomaterials, 25, 2867-2875. http://dx.doi.org/10.1016/j.biomaterials.2003.09.048

[12] Wang, F.B., Di, S.C. and Yu, J. (2011) Biocompatibility Research of Medicine Titanium Alloy Coating by Microarc Oxidation. Advanced Materials Research, 189, 222-226.

[13] Harimkar, S. and Dahotre, N.B. (2007) Laser Assisted Densification of Surface Porosity in Structural Alumina Ceramic. Physica Status Solidi (A), 204, 1105-1113.

[14] Harimkara Sandip, P. and Dahotre Narendra, B. (2008) Characterization of Microstructure in Laser Surface Modified Alumina Ceramic. Materials Characterization, 59, 700-707.

[15] Mateos, J., Cuetos, J.M., Fernandez, E., et al. (2001) Tribological Properties of Plasma Sprayed and Laser Remelted $75 / 25$ Cr3C2/NiCr Coatings. Tribology International, 34, 345-351.

[16] Yerokhin, A.L., Snizhko, L.O., Gurevina, N.L., et al. (2004) Spatial Characteristics of Discharge Phenomena in Plasma Electrolytic Oxidation of Aluminium Alloy. Surface and Coatings Technology, 177-178, 779-784. http://dx.doi.org/10.1016/j.surfcoat.2003.06.020 
Scientific Research Publishing (SCIRP) is one of the largest Open Access journal publishers. It is currently publishing more than 200 open access, online, peer-reviewed journals covering a wide range of academic disciplines. SCIRP serves the worldwide academic communities and contributes to the progress and application of science with its publication.

Other selected journals from SCIRP are listed as below. Submit your manuscript to us via either submit@scirp.org or Online Submission Portal.
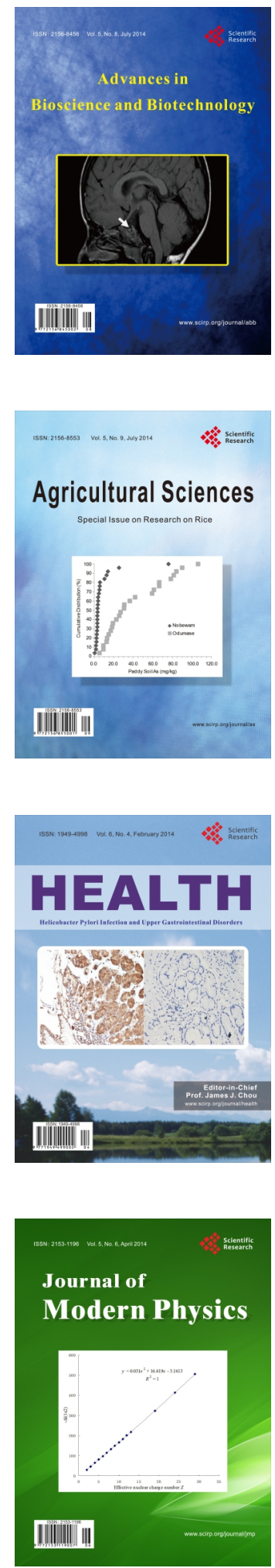
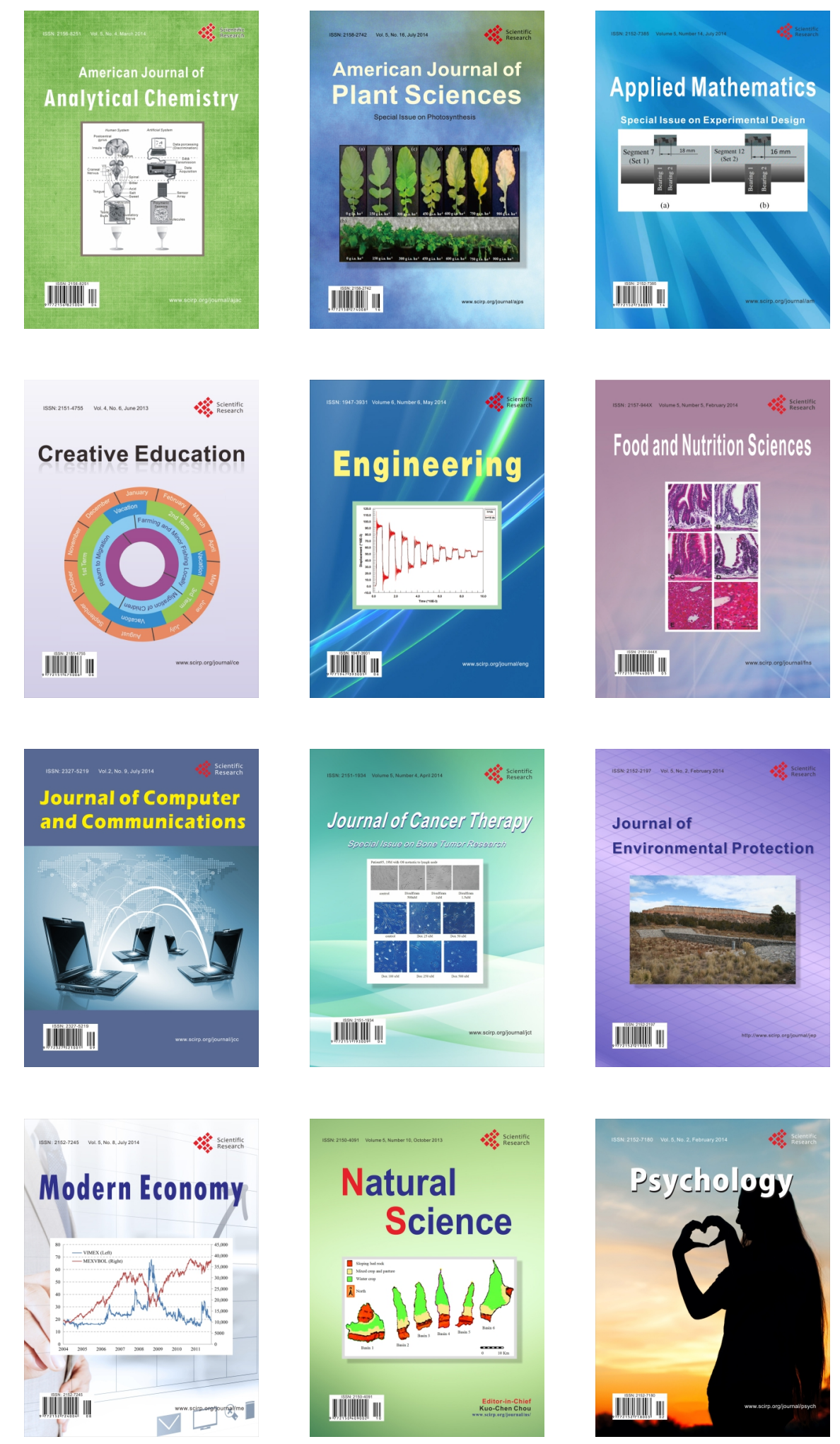